\title{
18
}

\section{A Quest for What We Ainu Are ${ }^{1}$}

\section{Shizue Ukaji (translated by Hiroshi Maruyama)}

I am 83 years old. Lately, I have been thinking that I will see my elder sister, parents and ancestors again in the world to come in the not very distant future (see Figure 13).

I came to Tokyo and married an ethnic Japanese. Turning 38 years old, I contributed an essay 'Ainu People, Let's Join Hands with Each Other' to the Asahi Shimbun Press. This essay is said to have triggered an Ainu movement for human rights in the metropolitan area of Japan. At first, I did not intend to inaugurate a political movement. I was just thinking that I want to die as an Ainu; in order to do so, I want to have gatherings with my brethren in Tokyo; I want to confirm myself as an Ainu by sharing joy, sorrow and sufferings with them. I have some Ainu blood in my veins. Spurred by the Ainu blood, I called out to my brethren to join hands with each other.

1 This contribution was originally a speech made by Shizue Ukaji to the third meeting of the Citizens' Alliance for the Examination of Ainu Policy, held at Hokkaidō University in Sapporo on 19 November, 2016. The original title of the speech in Japanese was 'Ainu narumono wo sagashimotomete'. 


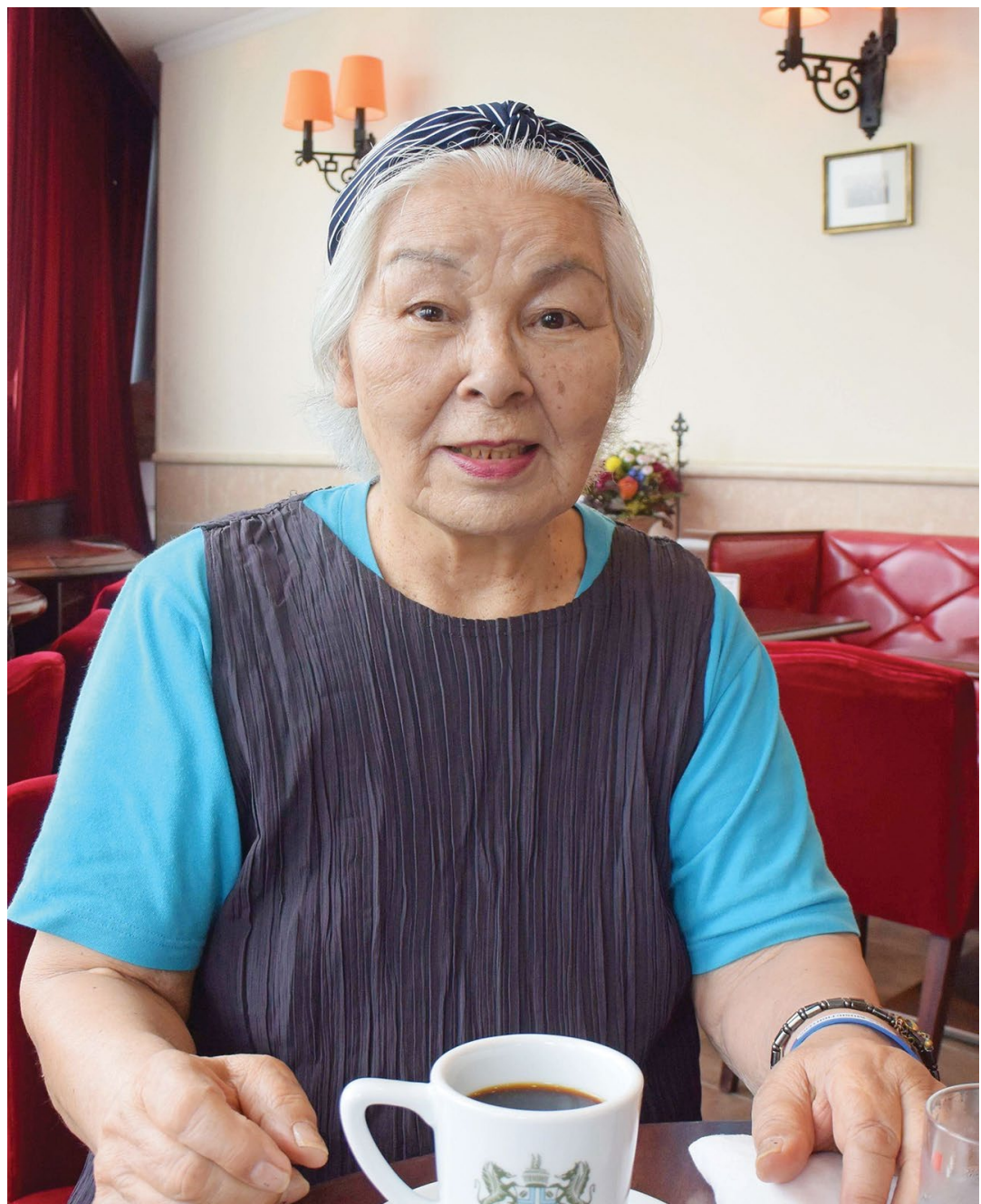

Figure 13. Shizue Ukaji, Ainu embroidery expert.

Source. Photographed by Hiroshi Maruyama, Sapporo Pirka Kotan, 1 December 2017. Used with permission.

At the age of 63, I started learning Ainu embroidery. After seeing an exhibition, it occurred to me that Ainu tales can be expressed by doing Ainu embroidery on Japanese clothes. Afterwards, I had the idea of using Ainu yukar (epics) for the expression of my image of a blakiston's fish owl - thus combining Ainu embroidery and Japanese clothes. In 2007, my illustrated tale named 'A Blakiston's Fish Owl and Salmon' saw the light of day. I call my pieces created by the combination of Ainu embroidery and 
Japanese clothes 'old cloth pictures'. In Ainu yukar, a variety of gods teach us what to do. In other words, Ainu yukar give us stories as to how we should behave as humans and how we should be connected to all things in nature. I found out that the spirit of the Ainu people is in Ainu yukar.

Under Japan's long colonial rule and its assimilationist policy towards them, our ancestors were losing the proud spirit of the Ainu. In my childhood, however, I saw fathers and mothers at their gatherings saying their prayers and eating, drinking, singing and dancing full of joy all night. At those moments, they could confirm their identity as Ainu. But now, these celebrations have become a thing of the past.

How many chances to feel happy do we Ainu have in our daily life? Happiness does not come from external sources. Instead, our own feelings about being Ainu make us happy. However exploited we have been throughout the modern and postmodern eras, we have an embryo of Ainu in our bodies, insofar as we are related to Ainu by blood. It is Ainu yukar that develops the embryo, I believe. I have heard that Ainu yukar were shortlisted for the Nobel Prize in Literature. Thankfully, our ancestors transmitted such a nice treasure to us. My only wish is to reclaim the spirit of we Ainu people by means of yukar. Reading yukar and talking to each other in the Ainu language must be the best literary education for Ainu. I wish we had such a place to gather and share.

In October 2017, I had an opportunity to make a speech at a festival hosted by Chasi-an-kar, which is an association of urban Ainu. The aim of the association is to build space for the gathering of Ainu. In the Greater Tokyo Area there is no public space for Ainu, unlike in Hokkaidō. We have to tackle this problem. There is, however, the Centre for Ainu Culture in the heart of Tokyo. It was built originally for the Tokyo office of the Foundation for Research and Promotion of Ainu Culture. This foundation was designated by the authorities concerned to be the sole corporation in the nation with authority to carry out the services provided by the so-called Ainu Promotion Act of 1997. We Ainu want to create our own spaces in which to gather through our own efforts.

After my speech at the above-mentioned festival, Mr Nishihara, who had been involved in the conservation of gorillas, talked about the Pygmies, an Indigenous people in the Republic of the Congo. The Pygmies have maintained a hunter-gatherer culture in the forest. They share natural resources in the forest with gorillas. Nowadays, 'civilised' humans encroach 
on those forests to the extent that gorillas and other wild animals are on the verge of extinction. After hearing Mr Nishihara's paper, I read a book about the Pygmies. I was attracted by a story of collecting honey in this book. When honey bees actively fly around in the forest, the Pygmies go out to look for beehives. The beehive that is found belongs to the person who found it, but honey collected from the beehive goes to others. Sharing what they hunt and gather with each other leads to peace-building in their community. After reading the book, I felt like finding the world described by Ainu yukar in the existing livelihood of the Pygmies. I realised that I have to translate the nature, Kamuy, and equality of people seen in Ainu yukar into practice. Today, war and violence are prevailing across the globe. Those who are entitled to call for equality and peace are Indigenous peoples, because we Indigenous peoples have the spirit of avoiding war and violence.

Japan is not far from the prevalence of war and violence in the world. Maintaining the norm of peace in Japanese society requires a restoration of the spirit of the Ainu people. The restoration should be conducted by Ainu themselves. If we Ainu continue to suffer from poverty, we can't afford the time to read yukar and to mingle with other Ainu. The Japanese Government has a responsibility for making it possible for the Ainu to make their living as Indigenous people.

The Council is for Ainu Policy Promotion, which was set up in December 2009, is based on the Report of the Advisory Council for Future Ainu Policy (July 2009). The council hosted by the Chief Cabinet Secretary, and has been discussing future Ainu policy for more than six years now. As yet, no final proposal has been announced. Nonetheless, public facilities for the Symbolic Space for Ethnic Harmony are being built as a fait accompli. Mr Kan, the Chief Cabinet Secretary, has pledged to complete these public facilities by the 2020 Olympic Games in Tokyo, to show to the international community Japan's effort to treat the Ainu respectfully as Indigenous people. I have never experienced throughout my life the Japanese Government treating us Ainu well. We Ainu can't understand why the Japanese Government believes that the completion of those public facilities will bring us happiness.

If the Japanese Government wants to use the term 'ethnic harmony' in order to build the above-mentioned public facilities, it is requested that the government make a formal apology to us Ainu for the historic injustices imposed on us. When those public facilities are inaugurated, 
we Ainu, in response, shall perform traditional rituals such as Kamuynomi and Icarpa. An apology from the government could heal the wounds of the Ainu that were caused by the colonisation of Ainu Mosir, or Hokkaidō. If the apology comes, it would be the first step towards reconciliation between Japan and the Ainu.

Finally, I will read my poem, which was composed at the moment when the earthquake and the subsequent great tsunami hit the northern part of mainland Japan on 11 March 2011. It was a spontaneous poem as an Ainu.

\section{Our land: A contribution to the Great East Japan Earthquake}

Did you feel heaviness?

Did you feel a pain?

We should have noticed and paid attention more deeply to an unusual change in your condition.

We should have had a means to perceive that a burden and pain lay on you.

A large number of people were washed away by the waves and returned to land with your burden and pain.

We survivors perceive the pain and pray to the gods with respect for the dead.

Lastly, I am grateful to Professor Yoshida, Professor Maruyama and others concerned with the Citizens' Alliance for the Examination of Ainu Policy, for giving me an opportunity to make a speech here. I am also hopeful that this citizens' alliance will attract support from many ethnic Japanese and the Ainu policy will proceed in accordance with Ainu people's right to self-determination. 
This text is taken from Indigenous Efflorescence: Beyond Revitalisation in Sapmi and Ainu Mosir, edited by Gerald Roche, Hiroshi Maruyama and Åsa Virdi Kroik, published 2018 by ANU Press, The Australian National University, Canberra, Australia.

doi.org/10.22459/IE.2018.18 